\title{
A cross sectional study on awareness of breast self-Examination and its practice in women of rural area in South India
}

\author{
Arun Bansode ${ }^{1}$, Sharad Prabhakarrao Ingle ${ }^{2}$, Shalaka Bansode ${ }^{3}$ \\ \{1Associate Professor, Department of Community Medicine $\left\{{ }^{2,3}\right.$ Assistant Professor, Department of Obstetrics \& Gynaecology $\}$ \\ Karuna Medical College, Vilayodi, Chittur, Palakkad, Kerala, INDIA. \\ Email: arunbansode821@gmail.com, shalakabansode@gmail.com sharad.22oct@gmail.com
}

\begin{abstract}
Background: Breast cancer is the most common cancer among women worldwide, and it can be detected at an early stage through self-examination. BSE is an inexpensive, simple, noninvasive method for early detection of breast tumors. Thus, knowledge about the procedure and consistent practice could protect women from severe morbidity and mortality due to breast cancer. This study assessed the knowledge and practice of BSE among women in Chittur taluk before participating in the study and after participating in the study. Methodology: This cross-sectional study was conducted for a period of 1 month in August 2018 in the Rural Health Training Centre (RHTC) service area of the Karuna Medical College Hospital. 250 women aged above 30 years were included in the study. A questionnaire was used to obtain information about the knowledge of breast cancer and BSE, attitude, practice of BSE. Women were explained about significance of BSE, how it is done, and the frequency to be done. Later after 1 week the same houses were visited and women were asked if they practiced BSE, the steps, their finding if any and whether they have visited surgeon. Results: Out of the 250 participants, $195(78 \%)$ were aware about breast cancer. 87(35\%) were aware about Breast Self-Examination (BSE). The percentage of women performing BSE increased after education about BSE from $21 \%$ to $85 \%$. After participating in the study and getting educated about BSE there was decrease in the number of women who do not know any step of BSE from $74 \%$ to $12 \%$. Conclusion: BSE is considered to be a simple, inexpensive, quick, noninvasive, nonhazardous intervention. Lack of knowledge about how to perform BSE is one of the most important reason amongst women for not performing BSE. Efforts should be made to develop educational programs to increase knowledge and practice of breast self examination among women.
\end{abstract}

Keywords: Awareness, Breast self examination, Breast cancer, Women.

\section{*Address for Correspondence:}

Dr Arun Bansode, Assistant Professor, Department of Community Medicine, Karuna Medical College, Vilayodi, Chittur, Palakkad, Kerala, INDIA.

Email: arunbansode821@gmail.com

Received Date: 22/11/2020 Revised Date: 19/12/2020 Accepted Date: 10/01/2021

DOI: https://doi.org/10.26611/10111721

This work is licensed under a Creative Commons Attribution-NonCommercial 4.0 International License.

\begin{tabular}{|l|l|}
\hline \multicolumn{2}{|c|}{ Access this article online } \\
\hline Quick Response Code: & Website: \\
\hline & www.medpulse.in \\
& \\
& \\
\hline
\end{tabular}

\section{INTRODUCTION}

Breast cancer is the second most common cancer worldwide and is the most common cause of cancer among women both in developed and also in developing countries. It is commonly associated with high levels of morbidity and mortality in India due to late presentation. Breast cancer is the most common cause of death due to cancer among women. ${ }^{1}$ Breast cancer reduces the life expectancy of the population at risk specially those between 31-50 years. Breast self examination can help in early detection of the disease. Studies have shown that most patients with breast cancer in developing countries present late for the first time at $2^{\text {nd }}$ and $3^{\text {rd }}$ stages. The reasons for late 
detection of breast cancer includes low awareness, presence of stigma, fear about pain during screening and fear about the disease, gender inequity, lack of screening test and infrastructure, low literacy, and low income levels. ${ }^{2,3}$ This indicates a need for increased community awareness of methods for early detection of the disease .There are various methods of early detection of breast cancer ,these include breast self examination, clinical breast examination and mammography screening. Breast self examination involves visualization and palpation of breast by oneself for size, shape, texture lumps and contour. Frequent breast self examination (BSE) has been shown to have favourable clinical outcome among breast cancer patients. ${ }^{4}$. Early detection helps in the treatment before metastasis and associated with excellent prognosis. Breast cancer screening was found to reduce the risk of mortality by $20 \% .{ }^{5}$. Despite the presence of various screening methods, majority of breast cancer cases can be detected by women themselves, stressing the importance of BSE.

\section{RESULTS}

Analysis was done to evaluate the practice of BSE in these women above 30years of age in Chittur taluk and to find out whether education about BSE can increase the practice of BSE. This study included 250 participants .Awareness of participants about breast cancer and Breast Self Examination (BSE) before participating in the study is shown in the Table 1 .

\begin{tabular}{|c|c|c|}
\hline & Yes & No \\
\hline Awareness of breast cancer & $195(78 \%)$ & $55(22 \%)$ \\
\hline Awareness of Breast Self Examination (BSE) & $87(35 \%)$ & $163(65 \%)$ \\
\hline Awareness Benefits of doing BSE & $160(64 \%)$ & $90(36 \%)$ \\
\hline
\end{tabular}

Out of the 250 participants, 195 (78\%) were aware about breast cancer. 87(35\%) were aware about Breast Self Examination (BSE). $160(64 \%)$ were aware that BSE helps in early detection of breast cancer. 52(21\%) were practicing BSE .Amongst the women who were practicing BSE most of the women (77\%) were performing BSE on irregular basis. 5(9\%) women were performing BSE monthly while 7(13\%) were performing BSE yearly. Out of 87 women who were aware about Breast Self Examination $67(77 \%)$ were educated more than $8^{\text {th }}$ standard and $33 \%$ were educated up to $7^{\text {th }}$ standard indicating the importance of education of women in awareness about BSE.

Table 2: Distribution of performing BSE

\begin{tabular}{cccc}
\hline & & $\begin{array}{c}\text { Before participating in the } \\
\text { study }\end{array}$ & After participating in the study \\
\hline Done BSE & & $52(21 \%)$ & $212(85 \%)$ \\
Performing BSE & Know all steps of BSE & $23(9 \%)$ & $47(22 \%)$ \\
& Know few steps of BSE & $41(16 \%)$ & $140(66 \%)$ \\
Reasons for not performing & Do not know/remember any step of BSE & $186(74 \%)$ & $25(12 \%)$ \\
BSE & Do not know how to perform & $112 / 198(56 \%)$ & $2 / 38(5 \%)$ \\
& Lack of Time & $20 / 198(10 \%)$ & $20 / 38(52 \%)$ \\
& No Privacy & $7 / 198(4 \%)$ & $1 / 38(3.3 \%)$ \\
& Do not understand & $25 / 198(13 \%)$ & $4 / 38(10 \%)$ \\
& Not interested & $34 / 198(17 \%)$ & $11 / 38(28 \%)$ \\
\hline
\end{tabular}

The percentage of women performing BSE increased after education about BSE from $21 \%$ to $85 \%$. Before participating in the study, lack of knowledge about how to perform BSE was the most common reason 112/198(56\%) amongst the women who were not performing BSE. $34 / 198(17 \%)$ women were not performing BSE because non interest in BSE. 25/198(13\%) women were not performing BSE due to lack of understanding of the steps 
of BSE. Lack of time (10\%) and non-availability of privacy $(4 \%)$ were also the reasons in these women for not performing BSE. After participating in the study and getting educated about BSE there was decrease in the number of women who do not know any step of BSE from $74 \%$ to $12 \%$. Educating women about BSE also improved their knowledge of performing BSE stepwise and there was increase in the women who know all the steps $(9 \% \mathrm{Vs}$ $22 \%)$ or few steps of BSE (16\%Vs $66 \%)$. Improvement in the number of women practicing BSE, women knowing all steps of BSE is shown in the figure 1.

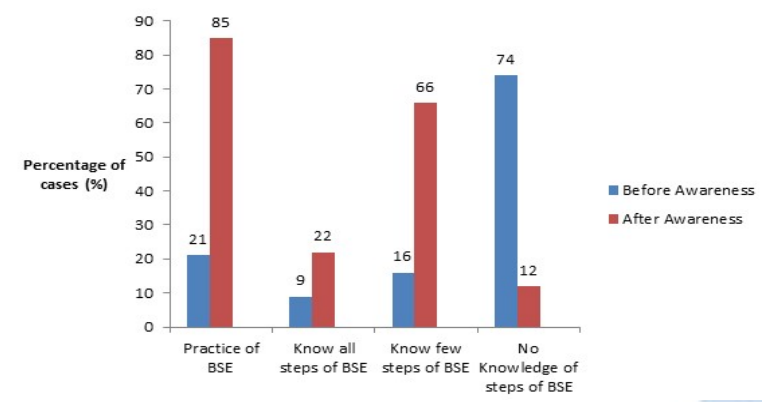

Figure 1: Distribution of cases about practice and knowledge of steps of BSE before and after participating and educating in the study

Breast cancer is the most common type of cancer affecting women worldwide and its prevalence is increasing particularly in developing countries where the majority of cases are diagnosed in late stages. The low survival rates in less developed countries can be explained mainly due to the lack of early detection programs resulting in a high proportion of women presenting with late-stage disease, as well as by the lack of adequate diagnosis and treatment facilities. BSE is an inexpensive, simple, noninvasive method for early detection of breast tumors. Thus, knowledge about the procedure and consistent practice could protect women from severe morbidity and mortality due to breast cancer. This study assessed the knowledge and practice of BSE among women in Chittur taluk before participating in the study and after participating in the study. Nearly $35 \%$ of the participants were aware of BSE. This proportion was almost close to the results reported by other studies ${ }^{6,7}$. Women with higher level of education had better knowledge regarding breast cancer and BSE than women with low education status. This was concordant with the reports presented by other studies ${ }^{8,9}$. In present study Out of 87 women who were aware about Breast SelfExamination $67(77 \%)$ were educated more than $8^{\text {th }}$ standard and $33 \%$ were educated up to $7^{\text {th }}$ standard indicating the importance of education of women in awareness about BSE. In the present study, proportion of women who practiced BSE regularly on monthly basis was $5 \%$ which was low compared to the observations made by
Parsa and Kandiah. ${ }^{10}$ Another South Indian study has also reported lower practice of BSE than the present study ${ }^{11}$ Positive relation between knowledge and practice of BSE has already been described. ${ }^{12}$ Hence, improving knowledge regarding the importance of BSE at community level would help sustaining the practice. The result of the current study revealed that the percentage of women performing BSE increased after education about BSE from $21 \%$ to $85 \%$. Similar to the results of study ${ }^{13,14}$ Despite the fact that $35 \%$ of the participants had heard about BSE, significant proportion of the participants had limited knowledge about BSE. Almost only 21\%participants were performing BSE. only $9 \%$ knew how to perform BSE, similar to the study by Zavare et al. ${ }^{14}$ In a study ${ }^{15}$ indicated that only $9.6 \%$ good knowledge towards BSE. In present study $9 \%$ women were knowing all the steps of BSE. There was improvement in the practice of BSE after participating in the study and getting educated about BSE. The percentage of women performing BSE increased after education about BSE from $21 \%$ to $85 \%$. Before participating in the study, lack of knowledge about how to perform BSE was the most common reason (56\%) amongst the women who were not performing BSE. After participating in the study and getting educated about BSE there was decrease in the number of women who do not know any step of BSE from $74 \%$ to $12 \%$. Educating women about BSE also improved their knowledge of performing BSE stepwise and there was increase in the women who know all the steps $(9 \% \mathrm{Vs} 22 \%)$ or few steps of BSE $(16 \% \mathrm{Vs}$ 66\%).Hence increasing the awareness about breast cancer, BSE, benefits of performing BSE is important. This can be achieved through health professionals who should create awareness about BSE and breast cancer through health information dissemination and health education programs. Finding of this study should be interpreted with the following limitations. The study was cross-sectional, so causal conclusions cannot be drawn. The study was carried out in RHTC) service area of the Karuna Medical College Hospital in Chittur taluk and therefore might not be representative of other places of the country. In general, and the practice of BSE may be different in other sectors of the population.

\section{CONCLUSION}

BSE is considered to be a simple, inexpensive, quick, noninvasive, nonhazardous intervention. This could be a useful measure for early identification of breast cancer in resource poor countries where accessibility to better screening methods is less.BSE can be used to as a measure to improve self-care among women. It is shown to increase the awareness regarding breast abnormalities and risk factors for breast cancer. Raising awareness may also empower women to follow healthy behaviors and health 
promotion activities. However, correct and thorough BSE technique has to be ensured and prompt and adequate medical need should be available when needed. There is a need to develop educational programs that can increase knowledge and practice of breast self examination among women

\section{REFERENCES}

1. GLOBOCAN 2012. International Agency for Research on Cancer. World Health Organization. PRESS RELEASE No. 223; 12 December, 2013. Available from: https:/www.iarc.fr/en/ media centre/pr/2013/pdfs/pr223_E.pdf. [Last accessed on 2016 Aug 10].

2. Taplin SH, Ichikawa L, Yood MU, Manos MM, Geiger AM, Weinmann $\mathrm{S}$, et al. Reason for late stage breast cancer: Absence of screening or detection, or breakdown in follow up? J Natl Cancer Inst 2004; 96:1518-27.

3. Agarwal G, Ramakant P. Breast cancer care in India: The current scenario and the challenges for the future. Breast Care (Basel) 2008; 3:21-7.

4. Foster RS Jr., Lang SP, Costanza MC, Worden JK, Haines CR, Yates JW. Breast self-examination practices and breast cancer stage. N Engl J Med 1978; 299:265-70.

5. Shapiro S, Coleman EA, Broeders M, Codd M, de Koning $\mathrm{H}$, Fracheboud $\mathrm{J}$, et al. Breast cancer screening programmes in 22 countries: Current policies, administration and guidelines. International Breast Cancer Screening Network (IBSN) and the European Network of Pilot Projects for Breast Cancer Screening. Int J Epidemiol 1998; 27:735-42.

6. Nafissi N, Saghafinia M, Motamedi MH, Akbari ME. A survey of breast cancer knowledge and attitude in Iranian women. J Cancer Res Ther 2012; 8:46-9.
7. Yerpude PN, Jogdand KS. Knowledge and practice of breast self examination (BSE) among females in a rural area of South India. Natl J Community Med 2013; 4:329-32. breast cancer

8. Yerpude PN, Jogdand KS. Knowledge and practice of breast self examination (BSE) among females in a rural area of South India. Natl J Community Med 2013; 4:329-32.

9. Yavari P, Pourhoseingholi MA. Socioeconomic factors association with knowledge and practice of breast self examination among Iranian women. Asian Pac J Cancer Prev 2007; 8:618-22.

10. Parsa P, Kandiah M. Breast cancer knowledge, perception and breast self-examination practices among Iranian women. Int Med J 2005; 4:17-24

11. Kommula AL, Borra S, Kommula VM. Awareness and practice of breast self examination among women in South India. Int J Curr Microbiol Appl Sci 2014; 3:391-4.

12. Doshi D, Reddy BS, Kulkarni S, Karunakar P. Breast self examination: Knowledge, attitude, and practice among female dental students in Hyderabad City, India. Indian J Palliat Care 2012; 18:68-73.

13. U. M. D. Gwarzo, K. Sabitu, and S. H. Idris, "Knowledge and practice of breast-self examination among female undergraduate students of Ahmadu Bello University Zaria, Northwestern Nigeria," Annals of African Medicine, vol. 8, no. 1, pp. 55-58, 2009.

14. ZavareMehrnoosh Akhtari, Juni uhamadHanafiah, Ismail Irmi Zarina, and Said Salmiah Md LLA, "Barriers to breast self examination practice amongMalaysian female students: a cross sectional study," SpringerPlus, vol. 4, 5 pages, 2015.

15. Nade Fon Peter, Assob Jules Cement Nguedia, and Kwenti Tebit Emmanuel NAL, "Knowledge, attitude and practice of breast self-examination among female undergraduate students in the University of Buea," BMC Research Notes, vol. 8 , no. 1 , article $43,2015$.

$$
\begin{aligned}
& \text { Source of Support: None Declared } \\
& \text { Conflict of Interest: None Declared }
\end{aligned}
$$

